\title{
Electric Energy Consumption of Bang-bang System and PID Control for Wiper System of Electric City Car
}

\author{
Nur Akhlis Sarihidaya Laksana, Munadi, and Mohammad Tauviqirrahman
}

\begin{abstract}
The technology developments in automotive are so fast. One of the supporting component in automotive is wiper system that acts as a cleaning water on the windscreen and the rear of the car. To give more convenience of drivers, the automatic wiper system is developed. The bang-bang system and the PID controller are simulated and applied to determine the response system and the level of energy consumption. In this work, the developed wiper system is installed in electric cars, in which the energy source comes from the battery. The results of the comparison between the simulation and application of bang-bang system and PID controller in terms of the response system and electricity consumption are used as the basis for selecting the automatic wiper system. The results indicate that the PID controller provides better response system and level of energy consumption compared to the bang-bang system, in which it is currently applied in most cars.
\end{abstract}

Index Terms-Wipe, modeling, bang-bang system, PID.

\section{INTRODUCTION}

Comfortability is very important in driving a car. One of its aspects is the cleanliness of windshield which contributes to the driver's visibility, especially during heavy rain conditions and driving in high speed. Therefore, there is a need for components that can clean the water properly. Wipers are the components on the car to remove the water on the windshield and the rear of the car. Therefore, the wiper system is expressed as a safety support system that works passively (working if required) [1], [2].

Most wiper system is currently still using materials from the rubber on its blade, and using a manual switch on the steering wheel area. Usually, the switch for wiper speed is classified to low, intermittent, and high. To facilitate the operation, currently, it was invented a wiper which is added with rain sensor. Generally, cars with rain censor are limited to luxury cars. However, it is assumed that the fate of the rain censor will be the same as ABS brake technology (Anti-break Locking System) that a few years ago was only applied to luxury cars, but it is now applied to various types of vehicles. Moreover, as the modern technology developed computerized system for cars, driving will turn into a comfortable thing. One the example is automatic wiper system with rain sensor shown in Fig. 1.

Manuscript received April 20, 2017; revised July 15, 2017.

Nur Akhlis Sarihidaya Laksana, Munadi, and Mohammad Tauviqirrahman are with theDepartment of Mechanical Engeneering Faculty, Diponegoro University, Jl. Prof. H.Soedarto, Tembalang, Semarang, Central Java, 50275, Indonesia (e-mail: akhlismesin2015@gmail.com, munadi@undip.ac.id, mohammad.tauviqirrahman@ft.undip.ac.id).

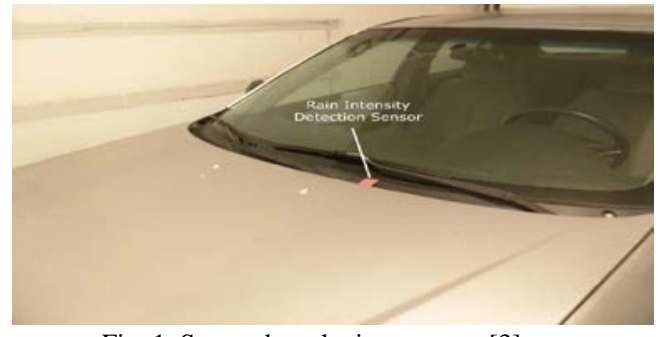

Fig. 1. Sensor-based wiper system [3].

The wiper rain sensor system works when water wets the surface of the sensor which is placed on the windshield. Furthermore, the signal received by the sensor is forwarded to the controller and activate the wiper motor. In the development of the automatic wiper system there is an automatic wiper which uses infrared sensor consisting of a signaling infrared (transmitter) and the receiver infrared signal receiver. The sensor works by firing a signal from the infrared transmitter and get received by the infrared receiver [4]. When working in normal circumstances without the rain water, the sensor is not working. It will work if the infrared signal is disturbed by raindrops rolling down the windshield as shown in Fig. 2.

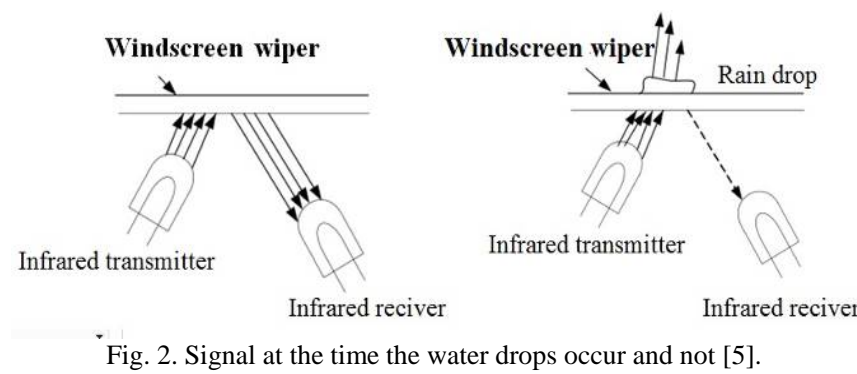

The automatic wiper system was also developed using a piezo-electric sensor to detect the intensity of the rain. This system uses a microcontroller as wiper controller and sensor as an input signal [6]. Some published works regarding to the automatic wiper system are detailed in [7], [8]. The system was developed to reduce driving distractions so that the driver will only focus on the primary task of driving. Kantawong and Janepumisart [9] developed an automatic wiper control for heavy rain conditions that lead to the onset of fog in front of the glass (mist control).

The inquiry carried out in this paper aims to explore the other side of the automatic wiper system that is in terms of energy used by wiper actuator. As a note, the electric cars which are similar to city car were developed and manufactured in our Laboratory. Indeed, the battery's energy is used not only used as a driving force, but also for other needs such as lights and wipers in which it uses a DC motor. A DC motor is the most widely applied actuator in the 
automotive and industry, especially for robotic actuators such as the in the control position of an arm robot manipulator [10], [11].

Therefore, the main objective of the present work is to develop the bang-bang system and control Proportional Integral Derivative (PID) which can adjust the wiper system automatically on an electric city car that has been made. This also leads to the investigation of the level of energy consumption required by the batteries between those two systems arrangement of automatic wipers.

\section{ReSEARCH Methodology}

\section{A. Mechanic of Wiper System}

The wiper system works by changing the rotational motion of motor wiper into wiper blade movement, i.e. the right and left. The developed system is a mechanical system that is a combination of an electric motor with worm gear to reduce wiper and linkage that converts the output of the wiper motor into motion back and forth on the wiper blade. The wiper systems are designed to operate at temperatures from $-30^{\circ}$ to $80^{\circ}[12]$.

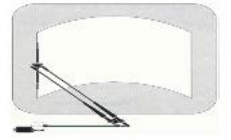

(a)

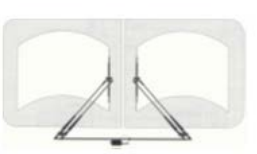

(d)

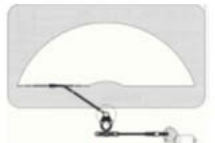

(b)

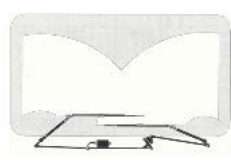

(e)

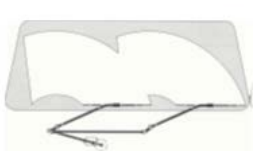

(c)

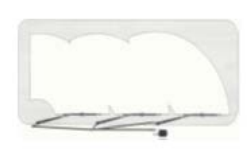

(f)
Fig. 3. The pattern of wiper system [13].

Nowadays, there are various patterns of wiper system in various vehicles. Fig. 3 shows the pattern wiper system, namely (a) wiper system with a pattern of parallel, (b) single-lever system with sectors wipe patterns, (c) a double-lever system with parallel wipe patterns, (d) opposed pattern double lever system with overlapping sectors wipe pattern, (e) tandem pattern double-laver system with overlapping sectors wipe patterns, and then (f) tandem-pattern three-lever systems with extra-wide sector overlapping wiper patterns. Accordingly, this work develops the wiper system or type of single lever system with one arm wiper systems for electric city cars.

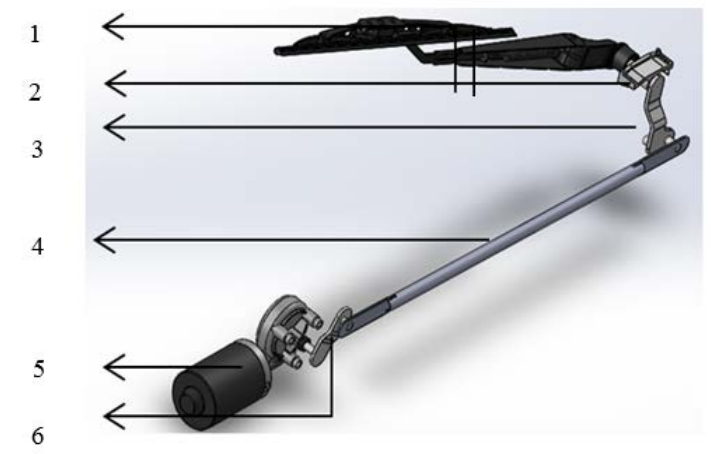

Fig. 4. The mechanim componen of wiper system.
In this study, the mechanism design of wiper system is adapted to the circumstances of the electric cars. Figure 4 shows the components of the wiper system which has been successfully created. The designed wiper system consisted of (1) wiper blade, (2) the holder, (3) joint, (4) link, (5) DC motors, and (6) joint wiper motor.

\section{B. Wiper System Using Simmechanics}

The prototype design is then simulated by using SimMechanics, so the mathematical modeling is not necessary anymore. As a note, the SimMechanics application creates mathematical modeling automatically. Fig. 5 shows the wiper systems modeling at SimMechanics. Furthermore, the model could be simplified into subsystems which became clearer for each component, and is shown in Fig. 6. Fig. 6 shows the subsystem of each system, ranging from the input of the input value, the wiper motor which is modeling for DC motor wiper, until the wiper arm and a wiper blade which is modeling the wiper arm and wiper blade on SimMehanics.

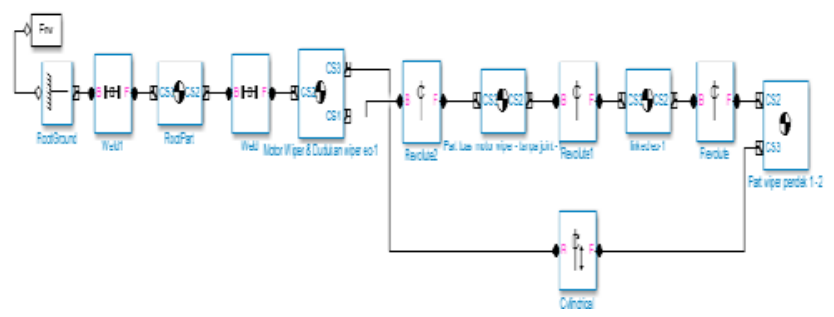

Fig. 5. The mechanism component of wiper system.

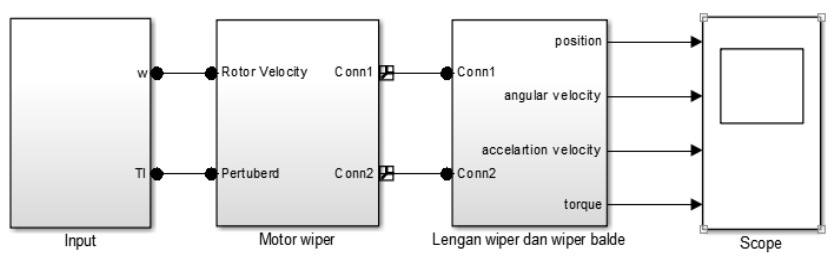

Fig. 6. Subsystem of the wiper system.

\section{Modelling of DC Wiper Motor}

DC motor is used as an actuator wiper as shown in Fig. 7. Further, the equation of DC Motor based on the modelling is as follows.

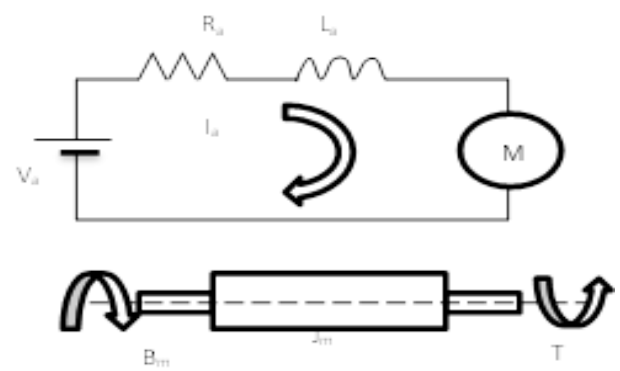

Fig. 7. An equivalent circuit DC wiper motor.

Based on Fig. 7, we got the Back-EMF voltage value shown by equation (1):

$$
E_{a}(s)=K_{b} \theta(s)
$$

Voltage $E_{a}$ is the result of the armature coil voltage caused by the movement of a coil in a magnetic field area. $K_{b}$ are constants for electromotive motorcycle, $\theta$ is the angular. 
Meanwhile, $V_{a}$ stands for voltage, $L_{a}$ is induction, and $R_{a}$ is the resistance of the motor. Therefore, the equation is as follows:

$$
V_{a}(s)=\left(L_{a} s+R_{a}\right) I_{a}(s)+E_{a}(s)
$$

Further, mechanical load is the part that discusses the relationship moment of inertia $\left(J_{m}\right)$ connected with the motor shaft and the friction caused by the air and bearing $\left(B_{m}\right)$, thus affecting a large torque generated and realized in the following equation:

$$
\begin{gathered}
T(s)=\left(J_{m} s^{2}+B_{m}\right) \theta(s) \\
T(s)=K_{a} I_{a}(s)
\end{gathered}
$$

Based on the equation (1) - (4), it could be considered that the function of the transfer between mechanical load and voltage is expressed as follows:

$$
G(s)=\theta / V_{a}
$$

$$
G(s)=K a / J_{m} L_{a} s^{3}\left(J_{m} L_{a}+J_{m} R_{a}\right) s^{2}+\left(B_{m} R_{a}+K_{a} K_{b}\right) s
$$

\section{PID Controller}

The PID controller is needed to control the wiper system automatically. Further, the system developed is bang-bang system (on-off system) and PID control. Bang-bang system is the term used in closed loop control systems without using a controller. The bang-bang system is shown in Fig. 8.

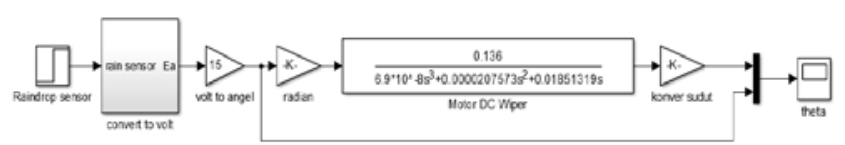

Fig. 8. Simulink of bang-bang system for a DC motor wiper.

Furthermore, PID control consisting of proportional control (P), integral (I), and derivative (D) is combined into one controller. This was done because each control has advantages that can be put together to get the ideal control. Accordingly, PID controller system block diagram is shown in the following Fig. 9.

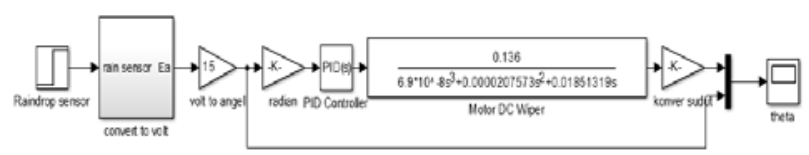

Fig. 9. Simulink PID control for DC motor wiper.

\section{E. The Implementation of Software and Hardware of Wiper System}

The design of software and electronic hardware is an important part in the planning of the wiper system as it would facilitate the reading in understanding the flow and processing scheme nets electric current flow in the wiper system. The aim is to make it easy in knowing any problems or disorders related to the electronic circuit.

Fig. 10 shows the hardware circuit of the wiper system on the electric city car. Fig. 11 depict the implementation of the automatic wiper system on an electric car wherein Fig. 11 (a) shows the windshield wiper system with one arm that is applied to the car and Fig. 11 (b) shows the hardware controller mounted on the automatic wiper. Moreover, the wiring diagram shown in Fig. 12.

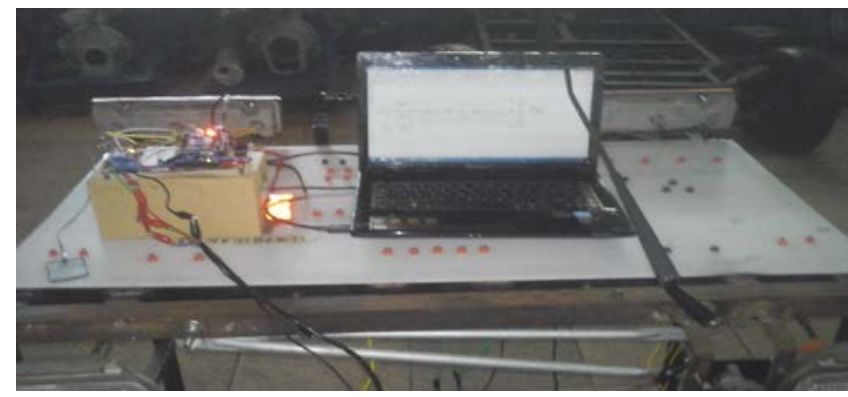

Fig. 10. The implementation of controller in wiper system.

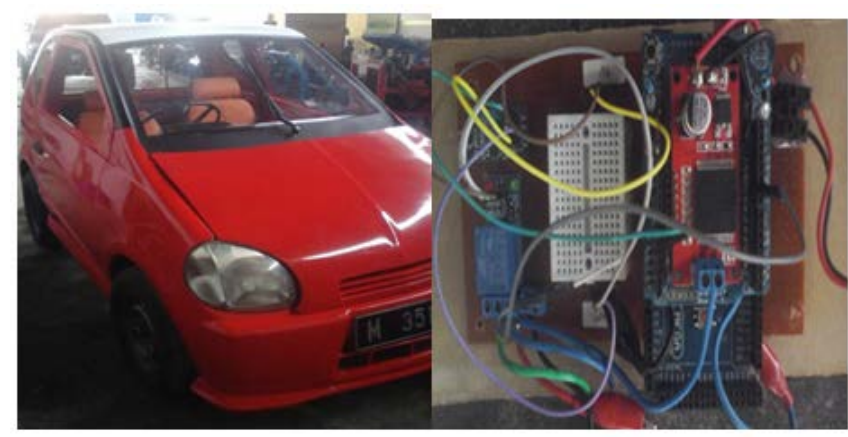

(a)

(b)

Fig. 11. The application of automatic wiper system, (a) wiper application on electric car, and (b) electronic controller hardware chain.

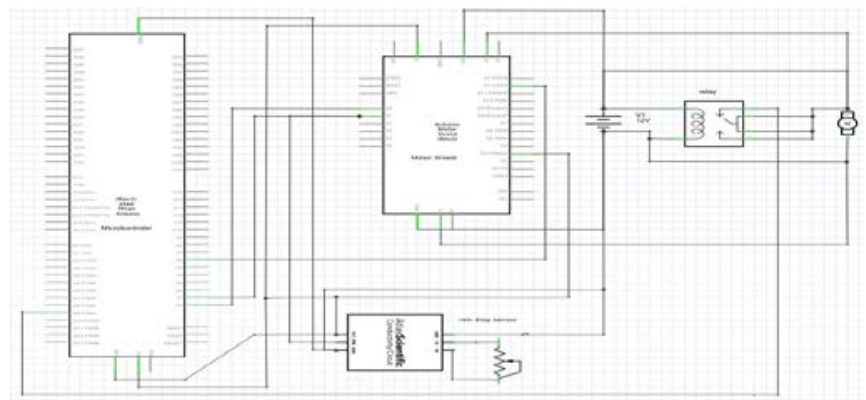

Fig. 12. The wiring diagram of the wiper system.

\section{RESULTS AND DISCUSSION}

\section{A. Simulation of Bang-bang System and PID Control}

Simulation is carried out to get an overview of the response system of wiper actuator. In addition, the simulation is performed using Simulink toolbox from Matlab. Moreover, the analysis plot's result with sisotool with the existing toolbox in Matlab is shown in Fig. 13. It can be found that the response system's rise-time value is $0.4 \mathrm{~s}$, overshoot $0 \%$, setting-time of $0.6 \mathrm{~s}$, and has a steady-state error value of $0 \%$. Figure 3 reflects that the controller is capable of converging towards a single point so that the system stands in a stable condition despite having a long response.

Further, the simulation with closed control without a controller to investigate the response system is also performed. By knowing response system, the value related to the kinematic motion can be determined. Figure 14 shows the response system of DC motor as the wiper actuator with bang-bang system. The red line is the set point and the blue 
line is the result of the simulation with input step by step time to $1 \mathrm{~s}$.

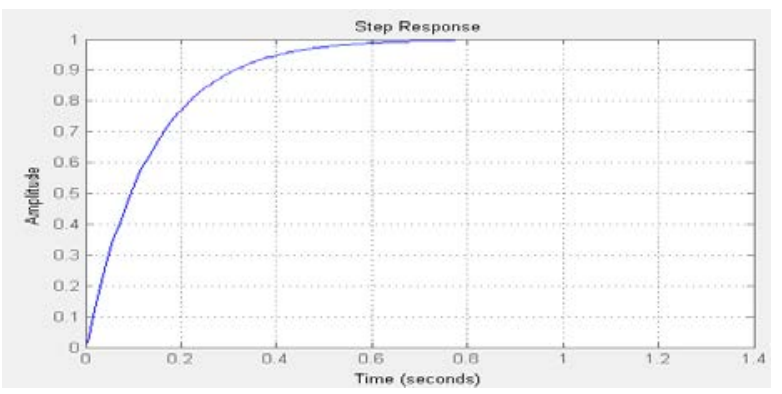

Fig. 13. The response system of PID control.

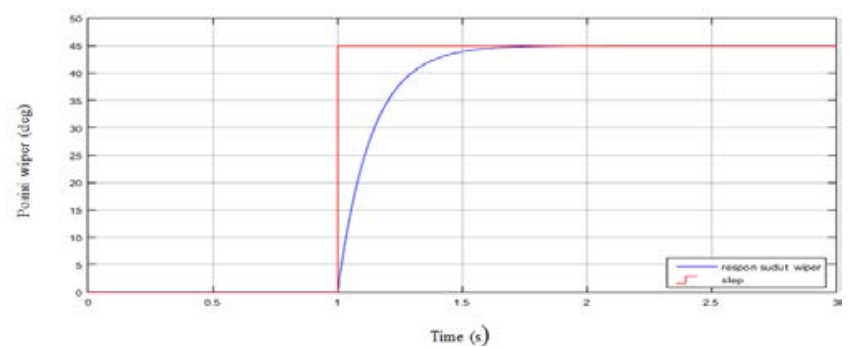

Fig. 14. Response system for positioning using bang-bang system.

It can also be observed that the results in Fig. 14 are similar to result as shown in Fig. 13. Thus, it indicates that the rise-time of $0.4 \mathrm{~s}$, overshoot $0 \%$, setting-time of $0.6 \mathrm{~s}$, and a steady-state error value of $0 \%$ are obtained.

The simulation results of PID is less maximum since it took quite a long setting time, so it is necessary to have tunning. Tunning is done directly in Matlab / Simulink. By such method, it is found that the gain of $\mathrm{Kp}$ is amounted to 22.02; $\mathrm{Ki}$ is 28.6; and $\mathrm{Kd}$ of -0.062 . These values are the best values to achieve the setting-time with fast response, as showed in Fig. 15. Figure 15 shows that when the rise-time value is $0.00665 \mathrm{~s}$, the system is experiencing overshoot up to $6.26 \%$ and setting time $=0.0297 \mathrm{~s}$. Based on the result, the system can be said to have a fast response and convergent.

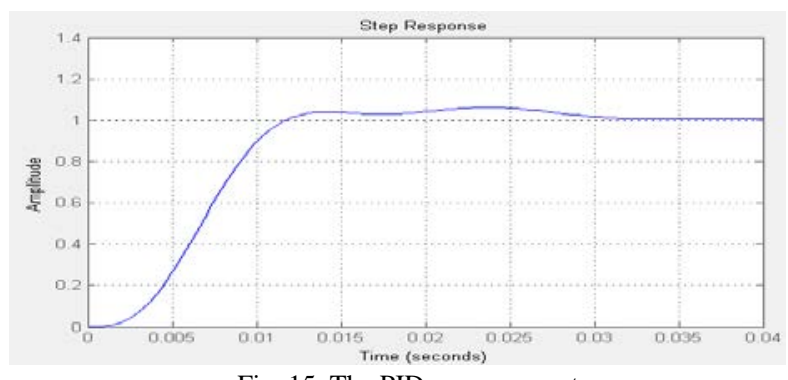

Fig. 15. The PID response system.

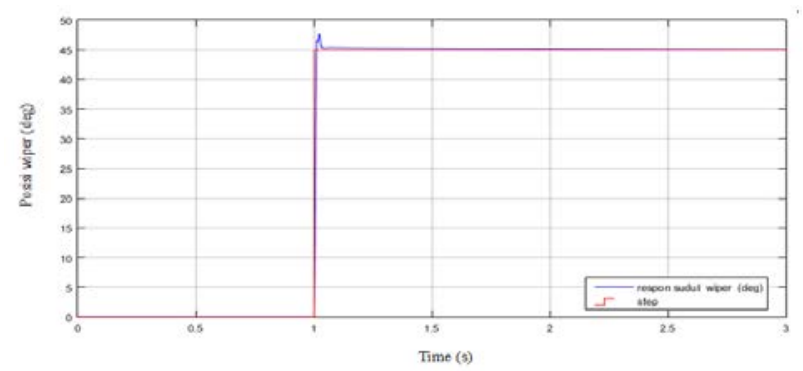

Fig. 16. Response positioning system with PID control.

The simulation for DC wiper motor by using PID controller is described in the following Fig. 16. The simulation results depict that the overshoot is $6.26 \%$, the rise time is $0.00665 \mathrm{~s}$ and the setting time is $0.2 \mathrm{~s}$. Based on Fig. 16 , the red line refers to the set of points and the blue line shows the simulation output with PID control.

\section{F. The Implementation of Bang-bang system and PID Control}

The next stage after the simulation is implementation. The program is developed in Matlab / Simulink and embedded in the hardware. The result of bang-bang system implementation is shown in Fig.17. This figure shows that the results of the implementation in accordance with the simulation in which the set-point is shown by the red line and the blue line is a bang-bang system response that leads the profile set-point as a reference input to be achieved.

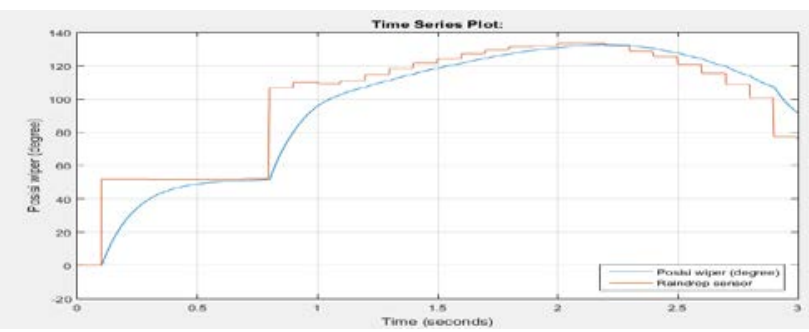

Fig. 17. The implementation of bang-bang system.

The next stage is the implementation of the PID controller and the results are shown in Fig. 18. The result of the implementation is in accordance with the simulation which has been done in previous section. The red line shows the set-point, while the blue line represents the condition of response system which formed lines that follow the movement profile of set-point as a reference input to be achieved.

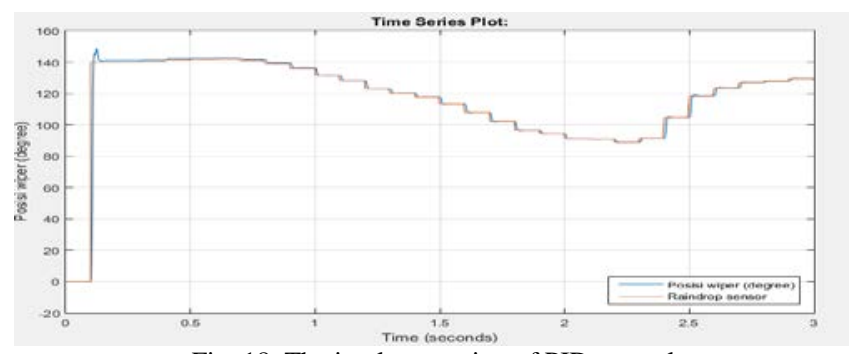

Fig. 18. The implementation of PID control.

If the bang-bang system and PID controllers are compared, so the difference in the response system is obtained as shown in Table I. It is found that the PID controllers have better performance than the bang-bang system.

TABLE I: RESPONE SYSTEM ANALYSIS

\begin{tabular}{ccccc}
\hline \hline Wiper system & $\begin{array}{c}\text { Rise Time } \\
(\mathrm{s})\end{array}$ & $\begin{array}{c}\text { Overshoot } \\
(\%)\end{array}$ & $\begin{array}{c}\text { Settling } \\
\text { Time (s) }\end{array}$ & $\begin{array}{c}\text { Steady State } \\
\text { Error (Ess) } \\
(\%)\end{array}$ \\
\hline $\begin{array}{c}\text { Bang-bang } \\
\text { system }\end{array}$ & 0,4 & 0 & 0,7 & 0 \\
PID control & 0,00665 & 6,26 & 0,0297 & 4 \\
\hline \hline
\end{tabular}

\section{B. Energy Consumption of Bang-bang and PID Control}

The main point in the development of this wiper system is the level of energy consumption of the battery on the use of bang-bang system and PID controller for electric city car. 
Again, the majority of vehicles are currently using bang-bang system, whereas for electric cars only uses battery, so the battery energy usage must be distributed efficiently. Based on this, we have planted bang-bang system and the PID controller to determine the level of energy consumed when the wiper system is being used. Additionally, Fig. 19 shows the energy consumption of the battery. Blue line shows the energy consumption for the bang-bang system, while the red line shows the battery's energy consumption PID control. When compared, the amount of energy consumption of bang-bang system reached 0.039 joules, whereas for the PID control 0.009 joules. As a result, it can be concluded that the automatic wiper system with PID control is more efficient for energy usage compared to those on bang-bang system.

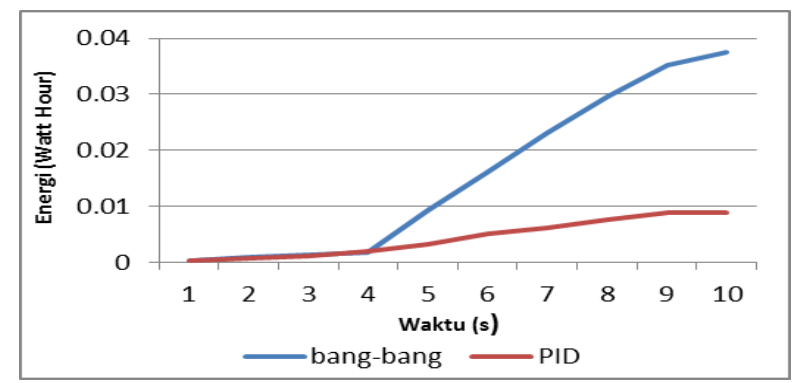

Fig. 19. The energy consumption of bang-bang system and PID control.

\section{CONCLUSION}

The automatic wiper system was designed, manufactured and developed for wiping the rain on the windshield. The system was designed to increase the comfort level of the driver. Moreover, this wiper system was developed on the electric car by applying bang-bang system and PID controller. This was done because an electric car has a characteristic to be saving in energy consumption of the battery. Meanwhile, the results of the simulation and implementation shows that the PID control is better than bang-bang system in response system. The test results shows levels of 0,039 joules of energy consumption for the bang-bang system and 0,009 joules for the PID control. As a result, it is more efficient to use the PID control, and also the PID control is supportive in the distribution of energy in the batteries of electric cars.

\section{REFERENCES}

[1] N. Sumarna, "Evaluation of the performance of front windshield Wiper on land transpor safety," International Refereed Journal of Engineering and Science (IRJES), vol. 2, no. 4, pp. 7-14, April 2013.

[2] A. Zolfagharian, P. Valipour, and S. E. Ghasemi, "Fuzzy force learning controller of flexible wiper system,” Springer, vol. 27, pp. 483-493. February 2016.

[3] L. Alszzawi and A. Cakravarty, "Design and implementation of a reconfigurable automatic rain sensitive windshield wiper," International Journal of Advances in Engineering \& Technology, (IJAET), vol. 8, no. 2, pp. 73-82, April 2015.

[4] Y.Y. Wang, J. Wang, and Z. F. Zhu, "Design of intelligent infrared windscreen wiper based on MCU,” Procedia Engineering, vol. 15, pp. 2484-2488, December 2011.
[5] H. Kajioka, K. Fujimura, and Y. Fujita, "Automatic wiper controller using optical rain sensor,” Fujitsu Ten Tech., no. 2, 1989.

[6] S. Dharmadhikari, N. Tamboli, N. Gawali, and N. N Lokhnde, "Automatic wiper sistem," International Journal of Computer Technology and Electronics Engineering (IJCTEE), vol. 4, no. 2, April 2014.

[7] Milkos, I. Zsolt., C. Ingealic, and C. C. Milkos, "Windshield wiper mechanism dynamic simulation in automotives,” International Journal of Engginering, vol. 9, no. 4, pp.1584-2673, 2013.

[8] A. G Basode, S. O. Rajankar and M. G. Ghatule, "Design and development of smart automatic windshield wiper sistem sistem fuzzy logic approach,” International Journal of Engineering and Science (ISSN), vol. 1, no. 1, pp. 14-20, August 2012.

[9] S. Kantawong, and N. Janepumisart, "Single wiper blade with new single link arm mechanism desain using fuzzy-PID control system,” in Proc. Internasional Conference on Knowledge and Smart Technology (KST), IEEE, March 2014.

[10] T. Deton, Automobile Mechanical and Electrical Sistems, Elsevier, Boulevard, Langford lan Kidington, Oxford: OX5 1GB 225 Wyman Street, Waltman, MA 02451, USA, p. 305, 2011.

[11] C. Alexandru and C. Pozna, "Dynamic modeling and contro of the windshield wiper mechanisms," World Science and Engineering Academy and Society (WSEAS), vol. 8, no. 7, pp. 825-834, July 2009.

[12] Munadi and T. Naniwa, "Experimental verification of adaptive dominant type hybrid adaptive and learning controller for trajectory tracking of robot manipulators," Journal of Robotics and Mechatronics, vol. 25, pp. 737-747, August 2013.

[13] Munadi and M. A. Akbar, "Simulation of fuzzy logic control for DC servo motor using arduino based on MATLAB/simulink,” in Proc. 2014 IEEE International Conference on Intelligent Autonomous Agents, Networks and Systems (INAGENTSYS), August 2014, pp. 42-46.

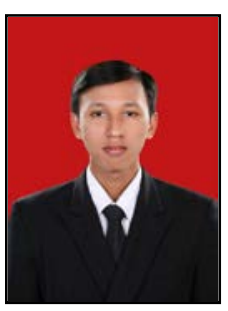

Nur Akhlis Sarihidaya Laksana was born on March 5, 1991 in Pemalang. His B.E. degree in the Dept. of Education Mechanical Engineering at Semarang State university in 2009. He as a student master programe in Diponegoro University.

He takes mechanical engineering as a major field study automotive engineering and control engineering as a minor field study. His research interests are automation system.

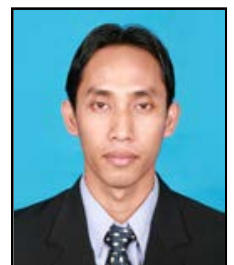

Munadi received the B.E. degree in mechanical engineering from Diponegoro University, Semarang, Indonesia, in 2001. From 2001 to 2005, he was with Pura Group Corp., Kudus, Indonesia. In 2007, he received the M.E. degree in mechanical engineering from Bandung Institute of Technology, Bandung, Indonesia. In 2011, he received the Dr. Eng. degree in human and artificial intelligent system from University of Fukui, Fukui, Japan. From 2011, he was a lecturer with the Department of Mechanical Engineering of Diponegoro University. His current research interests relate to hybrid adaptive and learning controllers for robot manipulators, robotic, and automation system.

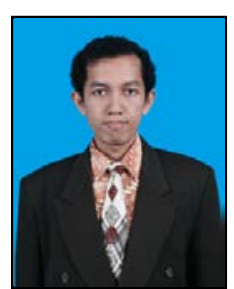

Mohammad Tauviqirrahman is a lecture in the Mechanical Engineering Depatment of Doponegoro University, Indonesia. His B.Eng. in mechanical enginerring from University of Diponegoro in 2003, and his M.Eng. in mechanical engineering from Institute Techology Bandung, and doctoral in laboratory for surface techology and tribology, University of Twente, the Netherlands. His research interests lubrication, Micro - Electro - Mechanical System (MEMS), numerical analysis, slip, surface texture. 